\title{
SARS-2 Coronavirus-Associated Hemostatic Lung Abnormality in COVID-19: Is It Pulmonary Thrombosis or Pulmonary Embolism?
}

\author{
Jecko Thachil, MD, FRCPath ${ }^{1}$ Alok Srivastava, MD, \\ ${ }^{1}$ Department of Haematology, Manchester University Hospitals, \\ Manchester, United Kingdom \\ 2 Department of Haematology, Christian Medical College, \\ Vellore, India
}

Semin Thromb Hemost 2020;46:777-780.

The coronavirus disease 2019 (COVID-19) pandemic has claimed several thousand lives since the first case was described in Wuhan, China, in December 2019. ${ }^{1}$ This has mainly been related to pulmonary complications presumed to be due to infection-associated inflammation and the resulting cytokine storm. ${ }^{2}$ Abnormal hemostasis was recognized early in the profile of these patients, with raised D-dimer being the most frequent abnormality in more than $70 \%$ of admitted patients with remarkably minimal changes in the remaining commonly measured hemostasis parameters (e.g., minimal prolongation of prothrombin time [PT] in some patients, and mild reduction in platelet count [almost all above $100 \times 10^{9} / \mathrm{L}$ ] but with markedly raised fibrinogen levels and no schistocytes ${ }^{3}$ ). As may be anticipated from these laboratory findings, bleeding has not been a notable feature of this illness. In early reports, these changes were considered consistent with disseminated intravascular coagulation (DIC) or sepsis-induced coagulopathy (SIC)., ${ }^{3,4}$ There is increasing recognition that the COVID-19-associated hemostasis abnormality (CAHA) may instead be resulting in localized thrombosis in the lungs, which has been reinforced by the fact that timely anticoagulation can be successful in reducing mortality of seriously unwell patients. ${ }^{4,5}$ This has led to recommendations for early intensive anticoagulation, in the absence of absolute contraindications, for all COVID-19 patients requiring hospitalization. ${ }^{6}$ Very recent postmortem reports have in fact confirmed this hypercoagulable state, with evidence of pulmonary thrombi, mostly microvascular, in all the four decedents evaluated. ${ }^{7}$ Recognizing the basis of the predominant lung pathology linked with the rapid clinical deterioration that is often unresponsive to ventilatory assistance and supportive care is critical to devising the interventions aimed at reducing mortality in these patients.

published online May 12, 2020
Issue Theme Maintaining Hemostasis and Preventing Thrombosis in COVID-19 -Part I; Guest Editors: Emmanuel J. Favaloro, PhD, FFSc (RCPA), and Giuseppi Lippi, MD.

Address for correspondence Jecko Thachil, MD, FRCPath, Department of Haematology, Manchester Royal Infirmary, Oxford Road, Manchester, United Kingdom M13 9WL (e-mail: jecko.thachil@mft.nhs.uk).

\section{Immunothrombosis and Pulmonary Microthrombi}

The hemostasis and immune systems have always been linked to one other. In evolutionary biology, it was recognized that both these systems shared the same purpose. ${ }^{8}$ It may be considered that a blood clot formed at the site of wound limits the loss of the most important constituent, the blood. But also, equally importantly, it stops any microorganisms invading the circulation through the breached vessel wall. Various components of the hemostatic system contribute to this immune function. Thrombin is the key player which plays a central role in linking the clotting pathways to the innate immune system. ${ }^{9}$ In addition, crosstalk between the various other coagulation factors, including the kallikrein-kininogen pathways on one side and cytokines, complement system, and the innate immune system on the other, is also well established. ${ }^{10,11}$ The main cellular component of the hemostatic system, the platelet, also plays a key role in this area. Several of its granular constituents are microbicidal and chemotactic; both functions may play a more important role than hemostasis in the setting of infections. ${ }^{12}$ The concept of a localized coagulation system in the lung as part of host defense or "bronchoalveolar hemostasis" is not recent. ${ }^{13}$ Indeed, the presence of a localized hemostatic system has been recognized for many years and attempts to modulate this in pathological conditions have been tried for at least a decade. ${ }^{14-16}$ These measures have not always been successful and localized pulmonary microthrombi continue to cause mortality in severely ill patients. ${ }^{17}$

What then is the pathophysiology of pulmonary microthrombi in patients with COVID-19? Is it the intense inflammation related to the viral invasion of the lungs which triggers hemostasis activation? The growing evidence strongly suggests that some of the clinical features of COVID-19 infection

Copyright $\odot 2020$ by Thieme Medical Publishers, Inc., 333 Seventh Avenue, New York, NY 10001, USA. Tel: +1(212) 760-0888.
DOI https://doi.org/ 10.1055/s-0040-1712155. ISSN 0094-6176. 
(like hypoxemia) are driven by a localized thrombotic phenomenon where both platelets and endothelium come together to initiate thrombosis. Endothelial cells constitute almost a third of the cells in the alveolar component of the lungs and have the key receptors for the SARS-CoV-2 including the angiotensin-converting enzyme- 2 receptors. ${ }^{18,19}$ In addition to this well-described receptor, several others, including transmembrane serine protease 2 and sialic acid receptors, are shared by both the SARS-CoV-2 and the endothelial cells. ${ }^{20-22}$ Formation of thrombi in the microvasculature could thus be a part of the physiological effort to limit the viral invasion. Marked endothelial activation secondary to the inflammation could release a large amount of von Willebrand factor (VWF), which could then swamp the VWF-cleaving protease, ADAMTS-13, leading to platelet aggregates that could also contribute to microthrombi. ${ }^{23}$ Although this feature is characterized in the well-known systemic microangiopathic hemolytic disorders, thrombotic thrombocytopenic purpura and hemolytic uremic syndrome, in COVID-19, this process is limited to the lungs, and systemic evidence of microangiopathy may not be evident in all cases. Limited thrombotic microangiopathy (TMA) can present as pulmonary hypertension, as reported in patients with TMA secondary to Cobalamin C deficiency and pediatric stem-cell transplantation. ${ }^{24,25}$ Similar organ-limited TMA is very familiar to renal pathologists.

\section{Pulmonary Microthrombi versus Pulmonary Emboli}

It is important to distinguish pulmonary microthrombi from pulmonary emboli in COVID-19 patients. Clinically, there are several situations where thrombi in the lungs could be overlooked in patients presenting with COVID-19 symptoms to hospital:

- Lack of awareness of hypercoagulability in COVID-19.

- Attribution of respiratory symptoms to severe pneumonia.

- Increasing oxygen requirements in patients admitted to hospital attributed to worsening pneumonia or acute respiratory distress syndrome.

- Inability to perform imaging due to work overload on the radiology department or the need for social distancing.

- Absence of deep vein thrombosis (DVT) in the limbs does not imply absence of pulmonary thrombi. ${ }^{26}$

It is well known that over half of the patients otherwise identified to have pulmonary embolism in the pre-COVID-19 era also have evidence of DVT in the lower limbs. ${ }^{27}$ For this reason, in patients in whom computed tomography imaging may be less desirable (e.g., pregnancy or severe renal impairment), some clinicians (not widespread practice) perform ultrasound Doppler of the lower limbs to check for thrombi and treat with therapeutic anticoagulation, if identified. ${ }^{28}$ However, this is not the case in patients with COVID-19, where DVT is not found in most patients, and pulmonary microthrombi are the result of local hypercoagulability, and not secondary to embolization from the lower limbs. For this reason, ultrasound surveillance may not be enough to identify such microthrombi. Patients who require critical care input, however, could subsequently develop venous thrombosis, which can then embolize to the lungs, further aggravating the lung dysfunction. Despite a critically ill patient being at a very high risk of thrombosis due to various reasons (including immobilization, underlying risk factors, muscle paralysis from sedation, and the use of vasoactive drugs), the diagnosis of pulmonary embolism can still be missed. ${ }^{29}$ This is not helped by the fact that prophylactic anticoagulation has high failure rate in critically ill individuals, but could be even worse in the extremely activated clotting system as seen in COVID-19. 5,30

\section{Does It Matter Whether It Is Pulmonary Microthrombi or Pulmonary Emboli?}

A recent publication looked at the structure and composition of thrombi and emboli using high-resolution scanning electron microscopy. ${ }^{31}$ The pulmonary emboli mirrored the most distal part of venous thrombi from which they originated. Also, the proportion of red cells in venous thrombi and pulmonary emboli was much higher than in arterial thrombi and more fibrin bundles were observed in the latter compared with the former. ${ }^{31}$ This finding is not clinically useful yet, but if we consider that platelets play a major role in pulmonary microthrombi compared with pulmonary emboli, it may be necessary to treat these patients with antiplatelet agents in addition to anticoagulants (the latter has proven track record only in those with pulmonary emboli). These antiplatelet drugs block platelet activation and may include conventional antiplatelet agents like aspirin or clopidogrel or intravenous forms like prostacyclin. Perhaps anti-inflammatory and anticomplement therapies are the answer to addressing the pathophysiology of pulmonary microthrombi in COVID-19, as the trigger for the microangiopathy is the inflammatory component. Very interestingly, immunocompromised individuals have been suggested to have had less pulmonary complications when infected with COVID-19. ${ }^{32}$ Also, may there be a role for nebulized or localized antithrombotic therapies, which can impact microvascular hemostasis as the coagulation system is activated and largely limited to the lungs at the alveolar level.

\section{Current Antithrombotic Strategies for Pulmonary Microthrombi}

There is consensus now that all patients admitted to hospital with COVID-19 receive prophylactic anticoagulation. ${ }^{6,33}$ It is also certain that those who have a confirmed pulmonary emboli receive therapeutic anticoagulation. Several trials have been established, looking at randomizing patients to receive prophylactic or therapeutic anticoagulation based on various clinical and laboratory markers, and results are eagerly awaited. Still several interesting questions remain:

- Should low-dose anticoagulants be considered for patients who may have a prothrombotic tendency and are currently in self-isolation but do not have severe symptoms of COVID-19?

- Are patients who are already on anticoagulants for previous thromboembolic episodes, mechanical heart valves, 


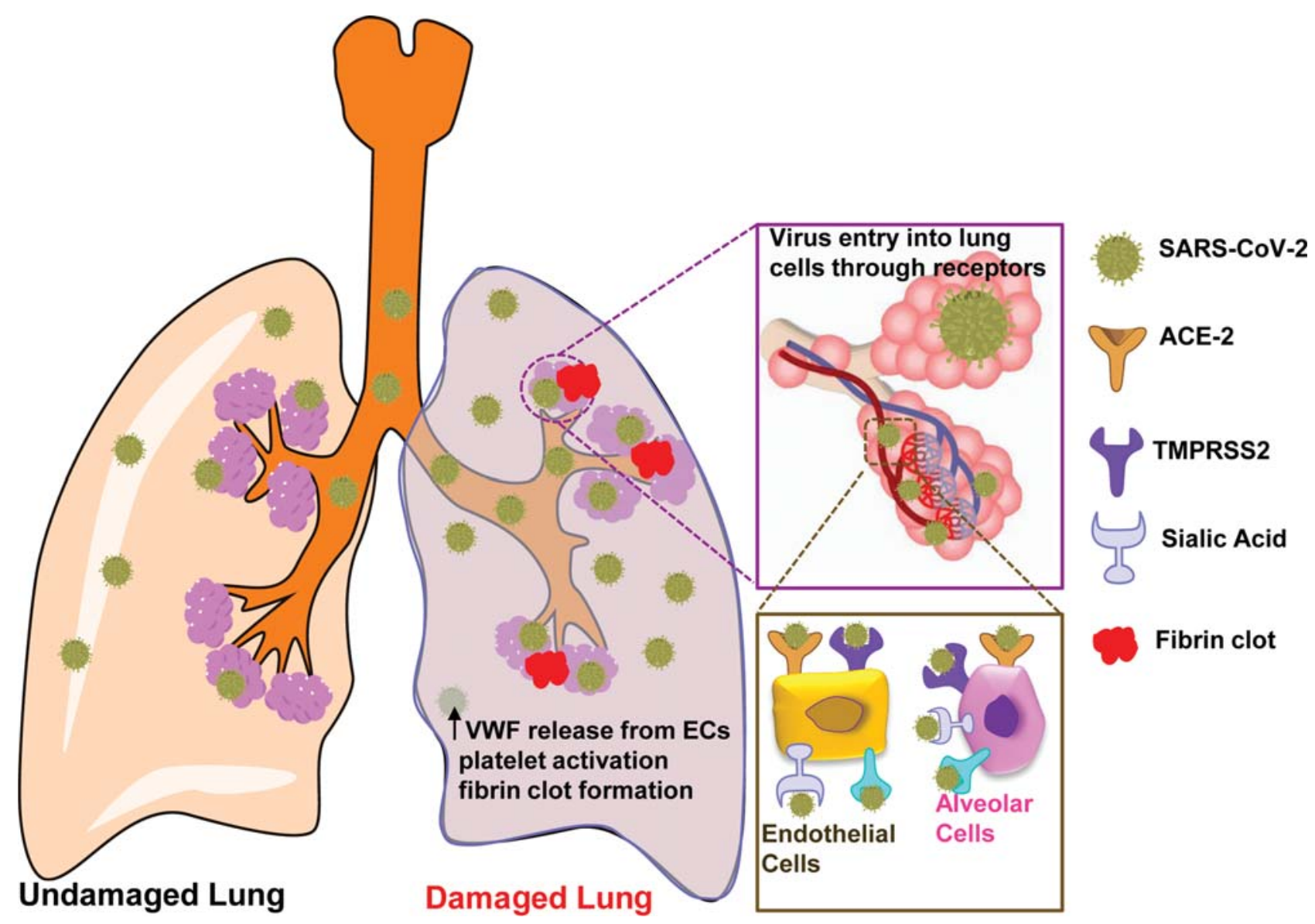

Fig. 1 COVID-19-associated hemostasis abnormality (CAHA) depicted in the lungs. In the undamaged lung (nonsevere COVID-19), the viral infection causes an intense inflammatory reaction. This inflammation can trigger activation of coagulation, which is an attempt to fight and block the viral invasion. In the damaged lung (severe COVID-19), unabated inflammatory reaction causes endothelial dysfunction leading to pulmonary microthrombi. Attempts to break down the extensive microthrombi are detected systemically as high D-dimer levels. ECs, endothelial cells; VWF, von Willebrand factor.

or atrial fibrillation protected from severe disease and complications if they indeed get infected with the SARS-2 corona virus?

- Will patients with underlying severe bleeding disorders such as hemophilia or Glanzmann thrombasthenia have less severe lung complications?

- Since there is a crucial link between inflammation and thrombosis, more so in COVID-19 patients, are patients who are on immunosuppressants less likely to get severe pulmonary disease and complications?

- Is there a role for antiplatelet agents in patients who progress to more severe disease while on therapeutic anticoagulation, since activated platelets are pathogenic in the lung inflammation?

- Where and how should anticomplement and anti-inflammatory therapies be used in patients with COVID-19, with the intention of dampening the coagulation response?

- Should patients who have recovered from severe COVID19 after being in critical care units be considered for longterm anticoagulation with low-dose anticoagulants, like those patients who had massive pulmonary embolism in the pre-pandemic era?

\section{Conclusion}

In summary, it is important to recognize that COVID-19associated hemostasis abnormalities, which we would term as "CAHA," represent a localized thrombotic phenomenon, which thus requires specific assessment and an appropriate therapeutic response (see - Fig. 1). Health care providers need to be cognizant of the significant possibility of pulmonary microthrombi in these patients and should keep a low threshold for investigating this complication in all patients. This is important because pulmonary thrombosis and pulmonary embolism may need different treatments. In the case of pulmonary microthrombi, this may be a combination of treatments in addition to anticoagulants. We are sure to win in this battle against an unseen but now well-known virus but should aim to learn a large amount quickly, regarding both its pathology and the potential therapies to limit shortterm and long-term morbidity and mortality in infected patients.

Conflict of Interest

None. 


\section{Acknowledgment}

We would like to thank Srujan K. Marepally for his help with the figure.

\section{References}

1 Chen N, Zhou M, Dong X, et al. Epidemiological and clinical characteristics of 99 cases of 2019 novel coronavirus pneumonia in Wuhan, China: a descriptive study. Lancet 2020;395(10223): 507-513

2 Guan WJ, Ni ZY, Hu Y, et al; China Medical Treatment Expert Group for Covid-19. Clinical characteristics of coronavirus disease 2019 in China. N Engl J Med 2020;382(18):1708-1720

3 Tang N, Li D, Wang X, Sun Z. Abnormal coagulation parameters are associated with poor prognosis in patients with novel coronavirus pneumonia. J Thromb Haemost 2020;18(04):844-847

4 Tang N, Bai H, Chen X, Gong J, Li D, Sun Z. Anticoagulant treatment is associated with decreased mortality in severe coronavirus disease 2019 patients with coagulopathy. J Thromb Haemost 2020. Doi: $10.1111 /$ jth. 14817

5 Klok FA, Kruip MJHA, van der Meer NJM, et al. Incidence of thrombotic complications in critically ill ICU patients with COVID-19. Thromb Res 2020:S0049-3848(20)30120-1. doi: 10.1016/j.thromres.2020.04.013. [Epub ahead of print]

6 Thachil J, Tang N, Gando S, et al. ISTH interim guidance on recognition and management of coagulopathy in COVID-19. J Thromb Haemost 2020;18:1023-1026

7 Fox SE, Akmatbekov A, Harbert JL, Li G, Brown JQ, Vander Heide RS. Pulmonary and cardiac pathology in Covid-19: the first autopsy series from New Orleans. MedRxiv 2020. DOI: 10.1101/2020.04. 06.20050575 [epub ahead of print]

8 Krem MM, Di Cera E. Evolution of enzyme cascades from embryonic development to blood coagulation. Trends Biochem Sci 2002; 27(02):67-74

9 Petzold T, Massberg S. Thrombin: a gas pedal driving innate immunity. Immunity 2019;50(04):1024-1026

10 Conway EM. Reincarnation of ancient links between coagulation and complement. J Thromb Haemost 2015;13(Suppl 1):S121-S132

11 Maas C, Renné T. Coagulation factor XII in thrombosis and inflammation. Blood 2018;131(17):1903-1909

12 Morrell CN, Aggrey AA, Chapman LM, Modjeski KL. Emerging roles for platelets as immune and inflammatory cells. Blood 2014;123 (18):2759-2767

13 Glas GJ, Van Der Sluijs KF, Schultz MJ, Hofstra JJ, Van Der Poll T, Levi M. Bronchoalveolar hemostasis in lung injury and acute respiratory distress syndrome. J Thromb Haemost 2013;11(01):17-25

14 Wygrecka M, Jablonska E, Guenther A, Preissner KT, Markart P. Current view on alveolar coagulation and fibrinolysis in acute inflammatory and chronic interstitial lung diseases. Thromb Haemost 2008;99(03):494-501

15 Idell S. Coagulation, fibrinolysis, and fibrin deposition in acute lung injury. Crit Care Med 2003;31(4, Suppl):S213-S220

16 Welty-Wolf KE, Carraway MS, Ortel TL, Piantadosi CA. Coagulation and inflammation in acute lung injury. Thromb Haemost 2002;88 (01):17-25
17 Juschten J, Tuinman PR, Juffermans NP, Dixon B, Levi M, Schultz MJ. Nebulized anticoagulants in lung injury in critically ill patients-an updated systematic review of preclinical and clinical studies. Ann Transl Med 2017;5(22):444

18 Letko M, Marzi A, Munster V. Functional assessment of cell entry and receptor usage for SARS-CoV-2 and other lineage B betacoronaviruses. Nat Microbiol 2020;5(04):562-569

19 Wan Y, Shang J, Graham R, Baric RS, Li F. Receptor recognition by the novel coronavirus from Wuhan: an analysis based on decadelong structural studies of SARS coronavirus. J Virol 2020;94(07): e00127-e20

20 Matsuyama S, Nao N, Shirato K, et al. Enhanced isolation of SARSCoV-2 by TMPRSS2-expressing cells. Proc Natl Acad Sci U S A 2020;117(13):7001-7003

21 Tortorici MA, Walls AC, Lang Y, et al. Structural basis for human coronavirus attachment to sialic acid receptors. Nat Struct Mol Biol 2019;26(06):481-489

22 Sardu C, Gambardella J, Morelli MB, et al. Is COVID-19 an endothelial disease? Preprints 2020:2020040204 [epub ahead of print] doi: 10.20944/preprints202004.0204.v1

23 Stockschlaeder M, Schneppenheim R, Budde U. Update on von Willebrand factor multimers: focus on high-molecular-weight multimers and their role in hemostasis. Blood Coagul Fibrinolysis 2014;25(03):206-216

24 Kömhoff M, Roofthooft MT, Westra D, et al. Combined pulmonary hypertension and renal thrombotic microangiopathy in cobalamin C deficiency. Pediatrics 2013;132(02):e540-e544

25 Jodele S, Hirsch R, Laskin B, Davies S, Witte D, Chima R. Pulmonary arterial hypertension in pediatric patients with hematopoietic stem cell transplant-associated thrombotic microangiopathy. Biol Blood Marrow Transplant 2013;19(02):202-207

26 Marongiu F, Mameli A, Grandone E, Barcellona D. Pulmonary thrombosis: a clinical pathological entity distinct from pulmonary embolism? Semin Thromb Hemost 2019;45(08): 778-783

27 Di Nisio M, van Es N, Büller HR. Deep vein thrombosis and pulmonary embolism. Lancet 2016;388(10063):3060-3073

28 Fard MN, Mostaan M, Anaraki MR. Utility of lower-extremity duplex sonography in patients with venous thromboembolism. J Clin Ultrasound 2001;29(02):92-98

29 Cook D, Crowther M, Meade M, et al. Deep venous thrombosis in medical-surgical critically ill patients: prevalence, incidence, and risk factors. Crit Care Med 2005;33(07):1565-1571

30 McLeod AG, Geerts W. Venous thromboembolism prophylaxis in critically ill patients. Crit Care Clin 2011;27(04):765-780

31 Chernysh IN, Nagaswami C, Kosolapova S, et al. The distinctive structure and composition of arterial and venous thrombi and pulmonary emboli. Sci Rep 2020;10(01):5112

32 D'Antiga L. Coronaviruses and immunosuppressed patients. The facts during the third epidemic. Liver Transpl 2020. Doi: 10.1002/ lt.25756

33 Bikdeli B, Madhavan MV, Jimenez D, et al. COVID-19 and thrombotic or thromboembolic disease: implications for prevention, antithrombotic therapy, and follow-up. J Am Coll Cardiol 2020. Doi: $10.1016 /$ j.jacc.2020.04.031 